\title{
Economía moral del fuero y cultura del conflicto en Guipúzcoa: la crisis de 1755
}

\author{
José María IÑuRRitegui Rodriguez
}

Proponer algunas reflexiones sobre las formas dominantes de conflicto en el ámbito territorial guipuzcoano durante el Setecientos es la intención que motiva estas páginas. El escrutinio y reconstrucción de un preciso curso de acción, los sucesos acontecidos en la provincia en 1754/55, la dimensión de análisis seleccionada. Y el criterio que justifica nuestra atención exclusiva a ese episodio, el reconocimiento en el mismo de un indudable potencial para promover e ilustrar la tesis de fondo que se sostiene, esto es, para perfilar que las citadas formas conflictuales de este territorio exento son las que funcionalmente derivan de la propia constitución comunitaria, de la comprensión del Fuero como estructurador de un ordein, y de su divergente lectura e interiorización como compuesto integral de costumbre y uso territorial ${ }^{1}$. Consecuentemente no es éste un trabajo, como podría con facilidad suponerse por las implicaciones de su encabezamiento, de historia propiamente social. Más bien lo que pretende es demostrar que desde esa estricta perspectiva mal podría comprenderse la con-

1 El sugerente concepto economia moral del Fuero -en cuanto código que informa una lectura de las claves forales, de sus propósitos morales y legales- ha sido acuñado como herramienta interpretativa del Setecientos guipuzcoano por ei profesor Pablo Fernández Albaladejo en una intervención crucial dentro del proceso de renovación experimentado recientemente por la cultura historiográfica vasca, y con respecto a la cual el débito de nuestro planteamiento resulta evidente: cfr. Fernández Albaladejo, P., «E] País Vasco: Algunas consideraciones en torno a su más reciente historiografía", R. Fernández (ed.), España en el siglo XVIII: HOMENAJE a PIERRE VILAR. Barcelona 1985, págs. 536/564, con el complemento de THOMPSON, E.P., Whigs and Hunters; The Origins of the Black Act. Londres 1977, págs. 258 y ss., pues con las lógicas precauciones eran las convicciones populares en torno a la Rule of Law allí apuntadas las invocadas por Fernández Albaladejo en la forja de este marco de comprensión. Por su carácter convergente con este enfoque interesa también el rechazo del Fuero como mera superestructura insinuado por LABORDA, J.J., «El arranque de un largo protagonismo: la recuperación comercial de Vizcaya a comienzos del xvill», Saioak, 2 (1978), págs. $136 / 181$, donde se contempla el ordenamiento foral como marco en el que se desarrollan las disputas aparejadas a la concurrencia de intereses antagónicos cuyo enfrentamiento en último término venía a certificar no su carácter accesorio sino la vigencia y capacidad integradora del sistema. 
flictualidad del modelo provincial que nos ocupa ${ }^{2}$. Se parte aquí, en ese orden de cosas, del entendimiento que lo social no es un mero agregativo que funciona según reglas estrictamente sociales o económicas sino que conviene analizarlo primeramente desde una consustancial dimensión - para este territorio entonces y más que nunca-constitucional ${ }^{3}$ : la foralidad.

Y precisamente un cualificado exponente de la comprensión más constitucional del Fuero como referente de una ancient constitution provincial basada en las ideas de costumbre, continuidad y equilibrio, o de su capacidad operativa, se reconoce en el momento del conflicto, como por ejemplo sucede en 1755. En la fecha una disposición de las Juntas Generales de Guipúzcoa -asamblea provincial de corporaciones que a su vez integraban representaciones no de individuos sino de otras tantas comunidades-, en concreto la renovación legislativa que sanciona con respecto al comercio de ganado, activa, en cuanto quiebra de un ordenamiento tradicional, una economía moral del Fuero - un preciso entendimiento del entramado socio-juridico consagrado en los códigos forales como esencial e indispensable para la supervivencia y equilibrio comunitario- que a su vez amenaza la quiebra del orden de las repúblicas en el plano local y provincial. Puede así captarse en primer instancia una dinámica conflictual relacionada con el consumo ${ }^{4}$, la gestación de lo que hemos denominado cultura del conflicto. Pero también, o mejor dicho fundamentalmente, la esencialidad del mismo, la naturaleza intrínseca del conflicto como elemento de un modelo provincial que ya cotidianamente no desconoce la violencia ${ }^{5}$.

2 Una lectura indispensable al respecto, y en general para la comprensión de lo aquí tratado, es PORTILlo VAldés, J.M., Monarquia y gobiemo provincial. Poder y constitución en las provincias vascas (1760-1808). Madrid, 1991, que no sólo estudia la fijación a lo largo del xvill de un modelo provincial amparado bajo el concepto de jurisdicción provincial y sostenido por la constante incorporación a esta categoría de aquellos aspectos que más directamente se relacionan con el gobierno interior de la comunidad, sino también la construcción tópica del discurso foral que lo sustenta. $Y$ en la misma línea de análisis de la realidad constitucional provincial, cfr. CLAVERO, B., "Las Juntas vascas ante el advenimiento de la Constitución española", en AA.VV., Juntas, Cortes y Parlamentos del Pueblo Vasco. San Sebastián 1988, y del mismo, "A manera de Vizcaya". Las instituciones vascongadas entre Fuero y Constitución", Anuario de Historia del Derecho Español, LVIn (1988), págs. 543/559.

${ }^{3}$ Cfr. como apoyatura, BRUNNER, O., "Das "ganze Haus" un die alteuropäische "Okonomik"», Neue Wege der Verfassungs und Sozialgeschichte. Gotinga 1968, págs. 103/127, y Estructura interna de Occidente. Madrid 1991; como contrapunto, KoCKA, J., Historia Social: concepto, desarrollo, problemas. Barcelona, 1989.

${ }_{4} \mathrm{Y}$ un estudio de continuidad para la segunda mitad del siglo XVIII lo certifica: cfr. IÑURRITEGUI, J.M., Monstruo indómito. Rusticidad y fiereza de costumbres. Foralidad y conflicto social en la Guipúzcoa del Setecientos. Memoria de licenciatura, U.A.M. Madrid, 1991.

5 Cfr. Gracia, J., Mendigos y vagabundos en Vizcaya (1766/1813). Bilbao 1993, y VIEJo YhaRRASSARRY, J., «Familia y conflictividad interpersonal en Guipúzcoa. Hernani, 1700/1750", Estudios de Historia Social, 34/35 (1985), págs. 7/81. 
La lectura del Fuero en términos de happy constitution articulada desde determinados sectores del entramado comunitario entonces se percibe y adquiere un sustantivo significado. El discurso de los infractores del acuerdo provincial ante las instancias forales - la diputación provincial- o reales - corregidor y Consejo de Castilla - no ubica el mal en la constitución provincial ni en el orden interno de la monarquía católica, ni mucho menos en los fundamentos profundos del sistema foral. Su crítica converge en la corrupción y el comportamiento amoral de algunos elementos de ese mismo universo comunitario. $Y$ el referente básico desde el que la economía moral vertebra su imputación es la propia figuración del Fuero como sistema históricamente trascendente -en el que pasado y presente constituian conjuntamente un ordo indisponible por actos positivos de voluntad- y como depósito de unas normas inquebrantables de comportamiento justo y moral ${ }^{6}$. Concretamente aquellas que por ejemplo en 1754/55 parecían omitirse.

I. El acuerdo más importante que adoptan las Juntas Generales de Guipúzcoa en su reunión de 1754, celebrada en la villa de Hernani, es la prohibición de extraer ganado fuera de la provincia. En el discurso provincial semejante medida no se contemplaba como gratuita ni novedosa. El elevado precio de la carne y la existencia de numerosos y recientes antecedentes eran al menos los dos pilares justificativos que ahora se apuntaban ${ }^{7}$. Un mes más tarde, en agosto de 1754, al componer y publicar la diputación provincial una normativa general reguladora del ramo el ciclo legislativo reformista parecía concluido ${ }^{8}$. La Provincia, no obstante, pronto podía constatar los problemas que su lógica generaba: la existencia de una serie de ángulos muertos en la reglamentación establecida y el más extremo enjuiciamiento global de la misma.

Al verse obligada la diputación en marzo de 1755 a implantar un sistema de guías complementario se reconocía y afrontaba la primera ver-

6 Para las referencias principales que guían nuestras consideraciones, cfr., THOMPSON, E.P., Tradición, revuelta y consciencia de clase. Barcelona 1979 -en especial "La economía "moral" de la multitud en la Inglaterra del siglo XVIII", págs. 62/134- y Società patrizia, cultura plebea. Otto saggi di antropologia storica sullinghilterra del Settecento. Turin 1981; BREWER, J. y STYLES, J., (eds.), An ungovernable people. The english and their law in the seventeenth and eigteenth centuries. Hutchinson 1983; y LANGFORD, P., A polite and commercial people. England, 1727-1783. Oxford 1989, esp. págs. 677/725.

7 Registro Junta Generales de Guipúzcoa (RJGG), 1754, págs. 16/17.

8 Archivo General de Guipúzcoa (AGG), Sección 1 ${ }^{\mathrm{a}}$, Negociado 10², legajo 87 (y en adelante realizo remisión numérica exclusivamente). 
tiente ${ }^{9}$. El aluvión de memoriales remitidos por los particulares de diferentes repúblicas denunciando el desajuste existente entre el dictado de la ley y su contexto de implantación, así como los comportamientos amorales que agravaban su aplicación - con el absentismo de los proveedores al frente- constataban la otra cara del problema. Consciente de la entidad y fundamento de estas reclamaciones, el máximo órgano provincial no contemplaba sin embargo la necesidad de proceder a un replanteamiento de la cuestión. Transferir toda la responsabilidad de las disfunciones detectadas al escaso rigor con que las autoridades locales procedían en la aplicación del acuerdo no era en el fondo sino una manera de omitirlas ${ }^{10}$. Ahora bien, ya en la primavera de 1755 y alarmada ante las reiteradas informaciones que recibía sobre la frecuencia y magnitud de las extracciones fraudulentas, comienza a vislumbrar la verdadera magnitud que adquiría la cuestión. Solicitar al corregidor Pedro Cano y Mucientes la apertura de una investigación al respecto pareció entonces oportuno ${ }^{11}$.

Estas averiguaciones -que corren a cargo del escribano del corregimiento Juan Bautista Landa y transcurren entre los días 30 de marzo y 4 de abril- de inmediato permiten acotar los perfiles del caso y anticipar un diagnóstico. Tras las declaraciones tomadas en la zona sur de la provincia, verdadero núcleo del problema, Landa puede ya certificar que la novedosa normativa se infringía y contrastar que el motivo no era la desinformación o el desconocimiento. El núcleo del conciso planteamiento qui manejaban todos los interrogados se sostenía sobre la apelación a la costumbre - «tradicional reciprocidad con las provincias vecinas»- y necesidad, referentes ambos en los que hacian residir la licitud de su comportamiento. Su prevención, consecuentemente, era respecto a la capacidad destructiva y disolvente de un orden tradicional demostrado por la prohibición, razón por la cual Landa emitía a continuación tres autos ordenando presentarse el día 11 de abril ante el corregidor a 16 vecinos (8 de Arechavaleta, 4 de Escoriza y 4 de Vergara) ${ }^{12}$. Y en ese preciso momento, cuando el procurador Juan Matías de Arreche articule ante el corregidor la defensa de quienes se definen como «pobres labradores e in-

AGG, Registro Diputación de Guiptizcoa (RDG), signatura (sig.) 111, 21/11/11755.

10 Ibidem, sig. 111, 25/III/1755 y 10/IV 11755.

Archivo Histórico Nacional (AHN), Consejos, leg. 214/3, fol. 9. Carta de la diputación provincial al corregidor Pedro Cano y Mucientes, 30/III/1765.

12 AGG, RDG, sig. 111, fols. 173/177 y AHN, Consejos, leg. 214/3, "Autos de oficio sobre levantamiento de gente intentado por la prohibición en la extracción de ganado de esta provincia, contra Esteban de Echeverría y Consortes", fols. 11/18, 21/38 y 86 y ss. 
quilinos», las líneas de fuerza y las implicaciones de su razonamiento comienzan a revelarse con nitidez.

La declaración ${ }^{13}$, primeramente, era reconocimiento de un delito pues confesaba una infración. Pero no lo hacía de forma llana y desnuda. La condición y calidad inducida de su actuación se acentuaba como atenuante de primera magnitud. No obstante el punto cardinal de la exposición era otro más audaz: rendir cuenta razonada de la coherencia de su comportamiento. Y en esa línea la vertebración de la exposición alcanzaba su cota máxima de tensión al desautorizar -lógicamente por negación- la imagen de necesidad y tradición esgrimida por las Juntas. Filtrar una serie de soluciones para la estabilización del ramo y la correción del régimen de abasto de carne cobraba así todo su sentido: no sólo aspiraba a evidenciar el carácter injustificado e inoportuno de una pieza legislativa, sino que dando un paso más trasparentaba la existencia de ideas y fórmulas dispares de regulación del orden de la república que ante la imposibilidad de alcanzar una concurrencia dialéctica terminaban confrontándose en la práctica cotidiana.

El éxito de la alegación fue sin embargo limitado. El corregidor decretaba su libertad ${ }^{14}$, pero en ningún momento se contempla la posibilidad de reconsiderar el acuerdo del 54. Además el mismo día 11 la diputación provincial tenía noticia de la aparición en el pórtico de la iglesia parroquial de Vergara de un texto anónimo relacionado con las citaciones cursadas por el corregidor y en general con la medida prohibicionista. De esta forma, y en virtud de su contenido, en lugar de concluirse el proceso era ahora cuando en verdad arrancaba:

"Señores Nobles vecinos labradores de Vergara: tenemos noticia entera, que está ente $V$ mdrs algunos presos por causa y motivo de que los bueyes han llevado a Vitoria. Y lo mismo estamos nosotros de Mondragón y Arechavaleta y Escoriaza y Salinas. $Y$ lo mismo estamos para presentar en el jueves que viene al corregimiento. $Y$ ahora determinan los señores mandantes de esta de Guipúzcoa hacer justicia rigurosa y prompta contra los culpados. $Y$ ahora determinamos ir obedientemente a entender lo que nos mandan. $Y$ si hace la demostración estamos juntos y congregados los dichos lugares hacer alto por motivo y causa que no se pueden conservar en ese modo los labradores pobres como está decretado en esta Provincia de Guipúzcoa. Y los señores mandantes hacen los decretos sin pensar y $\sin$ discurrir como no pueden conservar ni haun sea conservado jamás en esa manera. $Y$ si no puede vivir un Rey sin otro Rey como puede conservar la

13 Ibidem, fols. $81 / 83$.

14 Ibidem, fol. 84. 
Provincia de Guipúzcoa sin Alaba y sin Señorio de Biscaya: es muy imposible y se puede aturdir mirando a la razón. Estos mandantes toman las diferencias y escriven cartas a los Señores Justicia de Alaba y Señor de Biscaya y quedan embarasados a ellos. Y por motivo de esto sale y escandalizan toda la Provincia de Guipúzcoa, y Alaba, y Señorio de Biscaya, y quieren usurpar la sangre de los pobres. Consideren Vms. la razón y Júntesen todos los vezinos y congrégesen todos estar promptos con sus armas, y los que no tienen escopeta sacaran otras armas, lo que a Vms. les pareciere con ánimo y determinación valiente y estamos aquí juntos y congregados en ésta misma forma. $Y$ sea de salir de Salinas y bajaran para las siete de la mañana a Mondragón y tendremos que hacer. Y como está dicho antes no se debe hacer escándalo hasta ver que determina la justicia. $Y$ todo éste motivo y escándalo han sacado el Alcalde de Mondragón, como vachillero y endredador de la Provinca de Guipúzcoa y sus territorios, y de Segura, y de Vergara. Sacan cosas imposibles, y están en éste ánimo los de Alaba y los de Biscaya que tienen sus pasiones hablan conforme nosotros y dicen que no se ha conservado jamás, ni aun puede conservar. Los Veragreses tomen ánimo y valor y dar cuenta a uno y otro, de otra manera no puede salir la razón de nosotros. Y los señores Pacientes no conocen la probreza del próximo. No hay necesidad del extremo sino que sea el Justo malo de los mandantes. El ganado que hay en esta nobilísima Provincia de Guipúzcoa no se puede gastar el diezmo y por eso quedan perdidos los pobres labradores. $Y$ si no tienen con que valer con que puede pagar las deudas? No consideran eso los caballeros. $Y$ ellos los mismos estarán perdidos quieren comer la carne barata y las rentas añadidas y el trigo dar caro. Valer con todas sus cosas caro no se puede, ha menester andar como manda Dios. $Y$ no tenemos que decir más. $Y$ agur. Vergareses ánimo. Observando y guardando observancia muchas memorias, a todos los nobles vecinos de Bergara" ${ }^{15}$.

II. El texto no requiere comentario. Encierra un preciso entendimiento de la vida comunitaria. Reivindica su razón. Cataloga como indisponibles los principios morales y tradicionales que lo informan. Repudia su injustificado quebranto. Configura un espacio de razonamiento singular. Es economía moral en estado puro. Otro espacio de razonamiento que interesa en no menor medida ahora también emerge: lo delimita la lectura del texto que realiza la diputación provincial ${ }^{16}$. La «quiebra de la obediencia», la "confusión del orden y Constitución de la Provincia», y la imagen de la machinada de 1718 son los aspectos que la incardinan. Ya confiere así un sentido y atribuye una intención al texto anónimo. El problema raíz que

15 Ibidem, leg. 214/3, 2 "Autos de oficio sobre el descubrimiento de los culpados y cómplices en el papel sedicioso fijado y hallado en el Pórtico de San Pedro de Vergara, contra Estevan de Echeverría y consortes del lugar de Arechavaleta, vilias de Vergara y Escoriaza», fol. 9.

16 AGG, 1-10-87. 
subyace en su redacción no dejaba de percibirse: «para con la viclencia usar de la libertad de paso de particulares». No obstante el desencuentro en verdad se origina al detectarse un extremo eversivo que el pasquín expresamente no recoge: el antecedente de la machinada.

El inmediato reclamo de intervención cursado al corregidor y a las instancias militares obedecía por tanto más que a una realidad contemporánea a la amenaza ${ }^{17}$ y recuerdo de un suceso pretérito. El informe que Pedro Cano y Mucientes eleva al consejo de Castilla el día 13 de abril al respecto ${ }^{18}$, las sugerentes palabras del Marqués de San Millán al perfilar la estrategia provincial, su necesidad más imperiosa en la fecha ${ }^{19}$, o el dictado de la orden circular emitida por la diputación días después - para neutralizar desde su gestación el movimiento de protesta y garantizar el respeto al acuerdo de 1754- apuntan en esa dirección ${ }^{20}$. Y la comunicación ya desde la zona sur de la provincia del recien nombrado «Juez de comisión y delegado para la averiguación y prisión de los revoltosos», el consultor provincial Francisco Xavier Esparza, lo confirma: «se observa una grande tranquilidad sin que aparezca recelo de inquietud ni alboroto ninguno, que tampoco parece se ha experimentado antes de la llegada de la tropa» ${ }^{21}$.

No obstante que esa sea la clave en la que se interioriza la crisis y que desde ella se afronte su neutralización trasparenta ya en principio un dato sumamente significativo: la presencia y peso específico que la

17 Episodio que se adecúa notablemente a la tripología pre-riot -el clamoreo como insinuación del motín- propuesta para Francia por S.L. Kaplan, Breads, Politics and Political Economy in the Reign of Louis XV. La Haya 1976, I págs. 194/200.

18 «La Provincia se ha puesto en cuidado porque los pueblos en donde ha nacido la inquietud son los mismos que en el año de 18 la acusaron con escándalo a toda España, con el motín que llamaron de los Machinos o Machinada y del que resultaron tan funestas consecuencias. $Y$ como la casualidad de la guerra con Francia impidió el completo castigo, han quedado tan insolentes que cuando no quieren obedecer encuentran la amenaza de la Machinada, acobardan a la justicia y crece el desorden". Cfr, AHN, Consejos, leg. 214/3, "Autos de oficio sobre levantamiento", cit., Carta de Pedro Cano y Mucientes a Diego de Rojas y Contreras, 13/IV/1755.

19 «... cortar el daño cuando empieza a nacer y no dejarle tomar cuerpo, más en un Pais donde todavia se conserva la memoria de alguna triste y lamentable desgracia". Cfr. AGG, 1-6-23. Carta del Marqués de San Millán al comandante general Luis de Guendica, 11/IV/1755.

20 "... que pena de confiscación de bienes y las mayores y mas graves que se impondran a todo genero de personas, no se atreva alguna a levantar ni fomentar tumulto ni alboroto el más mínimo, ni pasen los vecinos y moradores de esta Provincia a hacer juntas entre si, ni con otros de fuera de ella, ni tener comberticulo alguno, ni anden en cuadrillas, ni tampoco levanten la voz, ni traten contra las providencias y restricciones acordadas por ésta la dicha Provincia sobre extración de ganado y su consumo en los pueblos de ella". Cfr. RDG, sig. 111, 15/IV/1755.

21 AHN, Consejos, leg. 214/3. "Autos de oficio sobre levantamiento", cit., Carta de Francisco Xavier de Esparza a Pedro Cano y Mucientes, 16/IV/1755. 
machinada - como elemento y forma de acción regeneradora aparejada a la economía moral del Fuero- conserva en el entramado comunitario vasco. El argumento exhibido por la provincia, y más concretamente aquella definición puntual que relaciona estrechamente todas las piezas de su discurso, la preservación de una constitución provincial amenazada por la machinada, introducía además un elemento en apariencia contradictorio. Idéntica imputación, desde supuestos diametralmente opuestos, los de esa economía moral del Fuero, realizan en su contra los infractores de la norma. Evidente resulta por tanto que los códigos forales, la dispar atribución de unos propósitos morales y legales a su espíritu, focalizan el debate y subyacen en las diferentes lecturas que ahora chocaban frontalmente.

Ambos extremos pueden constatarse con facilidad si se realiza una compulsa de la nueva ronda de interrogatorios ahora emprendida por Francisco Xavier Esparza en Mondragón, Arechavaleta y Vergara. La autoría intelectual y material del texto pronto quedaba fijada: el prófugo Esteban de Echeverria - vecino de Arechavaleta- lo ideó y su hijo José Antonio lo redactó. Otra serie de declaraciones resultan sin embargo más trascendentes. En especial, al poner de manifiesto relevantes datos sobre la conformación de la economía moral del Fuero, las emitidas por algunas de las principales figuras de la villa de Vergara: su alcalde Juan Bautista de Elcoro, el predecesor en el cargo Manuel Ignacio Elcoro, Melchor de Mecolalde, escribano de la villa, y tres futuros miembros de la Real Sociedad Bascongada de Amigos del País, Joaquín Moia, José Miguel Oiaso y Roque Xavier de Moiua, Marqués de Rocaverde 22.

La adscripción de la quiebra del orden de las repúblicas a la determinación de las Juntas con la correlativa equiparación entre paz y orden tradicional - «era preciso que hubiese libertad para extraer ganado si había de haber paz»-, la no menos teórica que extrema imputación de responsabilidades a la oligarquía provincial — «que todos los que habían concurrido a la expresada Junta General y acordado prohibir la extracción de ganado merecían les cortasen la cabeza»-, o la insinuación del carácter amoral de su actitud - «el interés particular nubla su razón»- ascendían a un primer y determinante plano. Vinculados todos estos aspectos a concepciones bien arraigadas sobre la rectitud en el proceder comunitario - «no atienden a las necesidades»- y a la conservación de un continente de tradición, práctica y costumbre - «ley nunca vista, contraria al uso y costumbre de la

22 Cfr, Ibidem, «Autos de oficio sobre el descubrimiento», cit. fols. 52/58, 60/65 90/100 y $104 / 106$, de donde proceden todas las citas que a continuación realizo. 
Provincia»- emergía entonces la fe en la forma extrema de manifestar el descontento, la amenaza de machinada: «es menester afilar las armas del pasado año de 1718 pues sólo la machinada hará arreglar este enredo". Y los supuestos de fondo desde los que se realiza su reclamo los trazaba con precisión un labrador vergares, Miguel de Irazabal: «¿porqué no se ha de valer cada uno de su ganado si hasta ahora era libre? ".

Las posteriores investigaciones ${ }^{23} \mathrm{del}$ juez comisionado en Mondragón y Escoriaza venían a recoger testimonios plenamente convergentes con las líneas directivas de este planteamiento rústico —en el lenguaje de la diputación- y una vez más acordes con las ideas recogidas en el texto aparecido en Vergara: reproducían las críticas contra los procuradores de las Juntas Generales de 1754 - «aquello era andar contra la sangre de los pobres y lo disponen así los magnates de la Provincia»- y contra las autoridades locales - «que la pidieron»-como interesados inductores de la medida; reaparecían las menciones a la tradicional e indispensable comunicación con las otras provincias exentas — «no se podía vivir sin libertad de extraer ganado ni las provincias de Guipúzcoa y Alava podían subsistir una $\sin$ otra"- y se recuperaba la figura catalizadora de la machinada - «si prosigue la prohibición se puede temer machinada»--. Por ello, contrastados todos los extremos, el 10 de mayo Esparza y el corregidor decretaban el ingreso en prisión de un total de 23 inculpados, ordenándose la retirada de la tropa que acompañó en su investigación al primero ${ }^{24}$.

III. La reforma emprendida en 1754 desde las Juntas Generales no podía dejar de ser conflictiva si más allá de una simple actuación de efecto sobre el comercio terminaba siendo interiorizada y planteada por un determinado sector provincial como trascendental reformulación y alteración de un uso - a modo de consuetudo- que había venido informando tradicionalmente la práctica en un campo primordial para el equilibrio comunitario. Además, y con independencia de las dificultades internas con que podía topar la concreta instrumentalización y aplicación de los acuerdos en un plazo inmediato, cobra un especial interés, por las importantes consecuencias que habrá de tener, la reacción que origina la medida en otra serie de ámbitos, incluido el propiamente monárquico, ajenos a la lógica empleada por el gobierno provincial en su resolución.

En concreto otro territorio aforado, Álava, era el primero en reaccionar. Lo hace ya en junio de 1754 y desde su más alta instancia, el diputado

23 Ibidem, fols. 128/144.

24 AGG, 1-6-23. 
general Gaspar de Álava, cuyo lenguaje — «difícilmente hallará V.S. disculpa que acredite lo resulto por esa M.N. Provincia y me niege facultad para que en mi territorio ponga igual limitación» ${ }^{25}$ - no admite duda. Pero sobre todo conviene subrayar que la visión global del problema que ofrecía en sus comunicaciones, el innecesario quebranto - bajo el «falso argumento de la penuria»- de una correspondencia interprovincial encumbrada como indispensable, guarda un notable paralelismo con las ideas que según sabemos poco después circulan abiertamente entre algún sector de la provincia. Como es evidente la lectura se realizaba desde supuestos dispares. La convergencia, no obstante, significa.

El episodio, valorado por la diputación como «voluntario despique de lo que en esta Provincia ha sido notoria necesidad» ${ }^{26}$, era además tan sólo el primer eslabón de un debate de mayor entidad que se precipita con la intervención del Consejo de Castilla. A él se dirigía a finales de mayo de 1755 Vergara para, en primera instancia, rendir cuenta de la razón que aconsejó la adopción de la prohibición: solucionar el desorden de un ramo. El deseo de establecer una correlación entre la aparición del texto anónimo y la secular actitud desafiante adoptada por un sector comunitario era sin embargo el punto más sustancial de su comunicación. $Y$ no resulta en este sentido casual que simultáneamente Cano y Mucientes incidiera sobre idéntico extremo en su informe al presidente del Consejo, Diego de Rojas y Contreras ${ }^{27}$. Compartían un diagnóstico — «la falta de castigo de la machinada de 1718 ha dado aliento a una gente tenaz y rústica y cada día amenazan con repetir los estragos cuando las determinaciones no se ajustan a su antojo"- y prescribian un único tratamiento: el castigo ejemplar. Era esta la propuesta de una villa y de una instancia real. La provincia, como tal, guardaba silencio. Y no sólo sobre el suceso. Ni tan siquiera la propia determinación de 1754 se había comunicado a la Corte. $Y$ es precisamente por aquí por donde se filtra el segundo desencuentro que afronta en la fecha. Que en su respuesta a Cano y Mucientes el consejo de Castilla relege a un segundo plano la cuestión del orden público - sobre la que tanto se había procurado llamar su atención- anticipa su lógica y marca unas distancias. Por supuesto la actuación de los detenidos y sus implicaciones se descalificaban expresamente, ordenando la

25 El acuerdo alcanzado en este sentido por la Junta Particular de Álava puede verse en Archivo General de Álava (AGA), Registro Junta General de Álava (RJGA), libro n 35, págs. 114/120. Cfr, las cartas de Gaspar de Álava a Pedro Cano y Mucientes del 10/VI/1754 y $1 / \mathrm{VII} / 1754$, así como la contestación del corregidor guipuzcoano el 15/VI/1754, en AGG, 1-10-87.

26 AGG, RDG, sig. 111, 28/IV/1754.

27 Cfr, ambas pieza en AHN, Consejos, leg. $214 / 3$, "Autos de oficio sobre el levantamiento", cit. 
continuación del proceso abierto contra ellos. Pero desde su óptica. el problema era sustantivamente otro: el haber adoptado la provincia sin contar con el parecer del Consejo una medida de ese calado, contraria a las líneas de pensamiento económico que en ese momento arraigan en el diseño monárquico:

«El Consejo de Castilla no puede aprobar la providencia que tomó la Provincia de prohibir la extracción de ganado vacuno, ni de cerda por ser contra el libre comercio que S.M. tiene mandado se observe... y asimismo ordena que no se ponga tasa en los precios dejando en libertad a los vendedores y compradores... y a la Diputación de la Provincia prevendrá Vmr. de orden del Consejo que un acuerdo de esta naturaleza no debió ponerse en ejecución sin solicitar la aprobación del Consejo, y que en lo sucesivo lo debe pedir para otros semejantes" 28 .

Probablemente, y vinculado con el discurso foral que se pretendía consolidar, el sentido de administración interior - exclusiva e irrenunciableque la diputación y la Junta General conferían a su gobierno provincial al proceder de aquella manera es el verdadero nervio que encuadra el debate. No se trata de una cuestión menor. Pero aquí puede llamar más la atención otra vertiende del caso: la relativa confluencia del discurso del Consejo con el articulado por unos labradores encausados que a mediados de mayo ya le remitían un pliego explicativo y justificativo ${ }^{29}$. Al confrontar el apunte del Consejo sobre «la necesaria comunicación y el comercio de unas Provincias con otras» con cierto fragmento del pliego - «desde inmemorial tiempo ha tenido aquella Provincia la correspondencia, trato y uniformidad con las confinantes»- al menos así se intuye. Ahora bien, el rasgo distintivo y la precisa esencia de la naturaleza de esta última lectura radica en su anclaje sobre concepciones totalmente desvinculadas de las directrices de una renovada tendencia del gobierno económico. Sus raices arraigan en la inmemorial costumbre y tradición.

Natural pobreza del suelo, costumbre, necesidad, condición de subsistencia, etc. Este era su lenguaje, el léxico que codifica las claves de un discurso rústico. No es sin embargo exclusivo. Con idénticos mimbres también se construye otro discurso de finalidad inversa, el de la diputación provincial. Las referencias y los referentes son los mismos. Y la manera en que unos mismos conceptos y concepciones podían dotarse de significados

\footnotetext{
28 Ibidem, Carta del Consejo de Castilla al corregidor de Guipúzcoa, 28/IV/1755.

29 Ibidem, "Pliego explicativo y justificado presentado por los reos de Guipúzcoa al Consejo de Castilla».
} 
divergentes según la manera en que fueran interiorizados y utilizados se plasmaba al responder al Marqués de San Millán a la acusación del Consejo que cifraba en "la mayor carestía en los mismos pueblos de lo que se prohibión el resultado del acuerdo de $1754{ }^{30}$. Ubicar decididamente la prohibición en las coordenadas de la foralidad era ya la única salida. Y así San Millán venía a solicitar que "sean sopesadas la escasez de mis frutos y la Constitución de mi País», que —-según sus palabras- siempre tuvo presente la monarquía. El dictado del capítulo $4^{\circ}$ del título $19^{\circ}$ y el capítulo $1^{\circ}$ del $22^{\circ}$-que sancionaban la libertad de comercio con Francia incluso en caso de guerra y la prohibición de extraer trigo de la provinciaeran citados como probatura ${ }^{31}$. Otra línea argumental complementaria ahora inaugurada, el perjuicio para la hacienda real que supondría la extracción de moneda si se abolía la medida, ejercía no obstante mayor efecto y lograba, al menos en apariencia, doblegar la resistencia del Consejo ${ }^{32}$.

La provincia, pese a todo, era consciente de la delicada situación creada por su iniciativa. Y en la reunión de la Junta General de 1755, celebrada en la villa de Elgoibar, optaba por reorientar la cuestión:

“Habiéndose reconocido que la prohibición de extraer Ganado no ha producido los favorables efectos que se prometía esta Provincia, y mediante las Reales Ordenes que mandan sea libre el Comercio de Frutos en todas las Provincias del Reyno; Acordó la Junta permitir por ahora la extracción libre de todo género de Ganado, a donde a sus dueños convenga» ${ }^{33}$.

Se optaba definitivamente por la derogación. El posicionamiento del Consejo de Castilla, pese a la última declaración formal, había resultado determinante. Pero la causa contra los infractores de la prohibición no se cancela. Ya sabemos que no era estrictamente su transgresión el sujeto en verdad enjuiciado. $Y$ ahora se evidenciaba.

IV. El 12 de junio de 1755 el fiscal Bentura de Telleria presentaba en nombre de la provincia la querella definitiva contra los encausados:

«... contraviniendo con sumo desprecio a las providencias útiles de buen gobierno acordadas por esta M.N. y M.L. Provincia de Guipúzcoa... han cometido el enorme y grave delito de intentar alborotarse, levantando gente

so $A G, 1-10-84$.

31 AHN, Consejos, leg. 214/3, "Autos de oficio sobre levantamiento...», cit., Carta del Marqués de San Millán a Diego Rojas y Contreras, 2/VI/1755.

32 Ibidem, Carta de José Antonio Yarza a Pedro Cano y Mucientes, 16/1/1755.

33 $A G G, R D G$, sig. $111,3 / V I / 1755$ para el orden del día en la convocatoria y RJGG, 1755 , págs. 8-9. 
con armas y causando inquietud en los pueblos... donde no solo perturbarían la paz y quietud pública sino que cometerían otros graves excesos, como son muertes, robos y otros que por su naturaleza producen los tumultos. $Y$ por estos tan gravísimos delitos son dignos dichos acusados de ser castigados con las mayores y más graves penas, para que sirviendo a ellos de condigno castigo sea para otros de escarmiento, a fin de que se guarde la debida obediencia y respeto a la Justicia y se extermine la voz y término de Machinada, usada y practicada con sobrada frecuencia... en grave perjuicio de la recta administración de Justicia» ${ }^{34}$.

La cuestión lo era de justicia, paz y buen gobierno. La referencia provincial básica, su propósito, es llamar la atención sobre un fenómeno, la machinada, para erradicar su figura como cauce de protesta. Con mayor claridad no podía declararse un objetivo. Subyacía una materia que posteriormente habrá de dar su juego: la apropiación del derecho para la definición de un orden interior que se decía amenazaba la machinada. Y con ello el carácter foral del suceso se fortalecería, al igual que al componer su réplica -el 25 de mayo en la carcel del corregimiento- los acusados. El nuevo manifiesto - de un sujeto cuya identidad ahora se precisa: «el miembro principal y el más numeroso de todo el vecindario de Guipúzcoa que es el de sus labradores»-, en la que aparecen coordinados los diferentes aspectos aludidos en el pasado de forma fragmentaria, ya no sólo ilustra la dualidad de perspectivas desde las que podía contemplarse el problema del ganado, sino que abiertamente afrontaba la definición de su concepción de la foralidad. Así, y soportando sobre su espíritu la construcción tópica habitual de su discurso — «libertad y exempción de estas Provincias", "norma que rompe la tradicional libertad que siempre ha habido en este País", etc- la economía moral del Fuero irrumpía en toda su dimensión, transparentando el grado de elaboración política de su planteamiento al enjuiciar la constitucionalidad de la medida a través de la descalificación de la representatividad de sus mentores: "para acordar y resolver esta novedad turbativa de la unión armoniosa de las tres Provincias convecinas e igualmente exentas, no habían tenido poderes especiales de sus repúblicas, ni antes de resolverla mantenido comunicación con ellas, como era regular en asuntos tan graves en este País» ${ }^{35}$.

Cuando el 19 de julio Esteban de Echeverría, refugiado desde abril en el convento de San Felipe de Madrid, declare voluntariamente ante el escribano de la Corte Juan de Navarro ser el «único y solo autor» del 
pasquín ${ }^{36}$, la principal acusación contra todos los detenidos se desvanecía y el proceso entraba en su recta final. El Consejo de Castilla creía llegado el momento de recibir los autos instruidos por el corregidor y así le solicitaba, como ya lo hiciera previamente en marzo, su remisión. La orden sin embargo no se había cumplido todavía en octubre, circunstancia que de acuerdo con las palabras de Unsategui respondía al deseo provincial «de que no se descubra la pasión con que se ha procedido y los defectos sustanciales de la sumaria, en que para coonestar la prisión se figuró un delito que nunca hubo ni cometieron mis partes» ${ }^{37}$. Pero finalmente, y tras emitir el 29 de noviembre su dictamen el fiscal del Consejo de Castilla, la real provisión del 27 de diciembre cerraba el caso:

«De la justificación recibida por el juez Comisionado y cuanto producen todos estos autos, únicamente se reduce a las quejas que se oyeron de aquellos naturales por que se les prohibió la extracción del ganado privándoles de la utilidad de este comercio, censurando el comparendo y la prisión en los terminos que se practicó, y quejándose de si las costas que lo dicho eran muy subidas, sin que se advierta expresión directa o subtancial que mire al suceso del año de 1718 conocido en ese País por la Machinada... Las expresiones y quejas que se notan con motivo de la referida prohibición son muy regulares en los pobres que tenían algunas reses, e igualmente lo es la oculta sustracción de ellas a las dichas Provincias... cuyo particular quedó purgado después que en la causa del Pasquín se hayan adelantado las justiciaciones tanto que sólo se trata de ello, pues en cuanto a el libelo sólo resulta lo que dejan expuesto los Echeverrias. En estos terminos y atendiendo a que el corregidor de Guipúzcoa en su informe estima se corte esta causa para cuyo fin ha remitido los autos originales en los que todavia no han producido los reos sus defensas, y que a mucho tiempo estan sufriendo la prision en que se hallan, con los correspondientes perjuicios a ella sin que ninguno haya tenido intervención en el papel... mandamos se archive esta causa condenando como se condena a Esteban de Echeverria y su hijo el estudiante José Antonio, a el primero en diez años de destierro de la Provincia y diez leguas de contorno y al hijo en seis, sin que cumplidos puedan entrar en ella sin orden de el Consejo, soltándose por el Corregidor a los demás reos, desembargandoles sus bienes, pagando mancomunados todos con los dichos Echeverrias, padre e hijo, las costas de esta causa, que ascienden a 6.541 reales de vellón apercibiéndoles que en adelante ni tengan juntas, ni hablen mal de las providencias de los superiores» ${ }^{38}$.

V. Por lo que implica de pública desautorización de su proceder no es difícil intuir lo extremadamente molesta que hubo de resultar para la

36 Ibidem, «Declaración de Esteban de Echevarría».

${ }_{37}$ Ibidem, Carta de Francisco de Unsategui a Diego de Rojas y Contreras, 12/X/1755.

38 $A G G, 1-6-23$. 
provincia la resolución final conferida a la crisis del ganado por el Consejo de Castilla. En ella, ciertamente, unas sentencias se contemplan, pero un escrutinio global las reduce de manera radical. Sólo la concepción y redacción del pasquín aparecido en Vergara el 11 de abril de 1754 se sancionan. Lo que parecía anunciarse como -y pretendía orientase haciauna etapa de definitivo afianzamiento de la autoridad provincial frente a la machinada quedaba en cierta medida bruscamente interrumpido. Desde la óptica del Consejo no se reconocía el argumento reiteradamente suscrito por la diputación, villas como Vergara o el corregimiento, esto es, la existencia de una fase larvada de machinada. Excluida quedaba en consecuencia la vía propuesta por el Marqués de San Millán, la conversión de la causa en un enjuiciamiento de rango mayor, su instrumentalización para el logro de la erradicación de una forma de protesta. El encuadre de la Corte más bien era el opuesto. Tácitamente incluso asimilaba la lógica de unos labradores. Y no tanto por la tipificación que confería a su comportamiento -transgresión de un acuerdo en lugar del reclamado posicionamiento amotinador- sino por la naturalidad que le reconoce implícitamente al catalogar como inmerecido cualquier castigo. El reclamo cursado respecto al orden público a petición de la provincia, el recuerdo de la debida obediencia a la autoridad, quedaba así subsumido en la sombra del que termina revelándose como verdadero objeto de debate: la naturaleza del acuerdo de las Juntas de 1754.

Otra es sin embargo la lectura del suceso que aquí conviene subrayar. En las coordenadas del proceso — anclado en la foralidad - de progresiva consolidación de las estructuras provinciales, el episodio analizado viene a demostrar la manera en que particulares piezas legislativas activadas al acuñarse un modelo provincial podían ser impugnadas por determinados sectores del ámbito comunitario cuyas formulaciones arraigan en una economía moral del Fuero, en una interiorización, interpretación y valoración del espíritu de los códigos forales. Nuevas manifestaciones de la pervivencia y vitalidad de semejante clave de lectura no tardarán en llegar, especialmente con la machinada de 1766. Pero los acontecimientos de 1755 ya rinden buena cuenta de la manera en que una conflictividad interior podía responder fundamentalmente a la propia configuración del entramado comunitario vasco y al tiempo resultar característica de todo un universo de relaciones comunitarias cuyo punto de referencia gira en torno a concepciones e interpretaciones diversas de la foralidad. 